Wright State University

CORE Scholar

Mechanical and Materials Engineering Faculty

Publications

Mechanical and Materials Engineering

1982

\title{
Measurement of Neck Development in Tensile Testing Using Projection Moire
}

\author{
Raghavan Srinivasan \\ Wright State University - Main Campus, raghavan.srinivasan@wright.edu \\ C. S. Hartley \\ C. Raju \\ J. Clave
}

Follow this and additional works at: https://corescholar.libraries.wright.edu/mme

Part of the Materials Science and Engineering Commons, and the Mechanical Engineering Commons

\section{Repository Citation}

Srinivasan, R., Hartley, C. S., Raju, C., \& Clave, J. (1982). Measurement of Neck Development in Tensile Testing Using Projection Moire. Optical Engineering, 21 (4), 655-662.

https://corescholar.libraries.wright.edu/mme/123

This Article is brought to you for free and open access by the Mechanical and Materials Engineering at CORE Scholar. It has been accepted for inclusion in Mechanical and Materials Engineering Faculty Publications by an authorized administrator of CORE Scholar. For more information, please contact library-corescholar@wright.edu. 


\section{Measurement of neck development in tensile testing using projection moire}

\section{R. Srinivasan}

State University of New York

Dept. of Materials Science and Engineering

Stony Brook, New York 11794

\section{S. Hartley}

Louisiana State University

Dept. of Mechanical Engineering

Baton Rouge, Louisiana 70803

\section{B. B. Raju \\ J. Clave}

University of Florida

Dept. of Materials Science and Engineering

Gainesville, Florida 32611

\begin{abstract}
The projection moire technique affords an accurate method of measuring the geometry of the necked region in a tensile specimen. Corrections to the measured stress, necessary to account for the triaxiality introduced by the neck, require values for the radius of curvature of the specimen at the minimum section. The spacing of fringes resulting from the interference between a grating projected on the specimen surface and a master grating not only provide information which permits calculation of the radius but also demonstrates any changes in symmetry resulting from plastic deformation. Results obtained by testing specimens of copper and mild steel having initially straight and initially curved profiles indicate that Bridgman's approach provides a self-consistent correction for triaxiality. However, comparison of incremental tests with continuous tests indicates that the development of neck geometry may be sensitive to the strain rate.
\end{abstract}

Keywords: incoherent optical techniques in experimental mechanics; projection moire; plasticity; necking.

Optical Engineering 21(4), 655-662 (July/August 1982).

\section{CONTENTS}

1. Introduction

2. Principles of measurement

2.1. Projection moire method

2.2. Theory of the method

2.3. Measurement of profile radius

3. Experimental procedure

3.1. Apparatus

3.2. Calibration of the instrument

3.3. Procedure

4. Results

5. Discussion

5.1. Calibration

5.2. Measurements on specimens

6. Conclusions

7. Acknowledgments

8. Appendix A: general equations of the moire fringes

9. References

\section{INTRODUCTION}

Uniaxial tensile tests of ductile materials often exhibit a period of flow localization, called "necking," prior to fracture of the specimen. Because of this phenomenon, a specimen having an initially uniform gauge section, such as a right circular cylinder, develops a locally reduced cross section, which decreases in size until failure. Necking introduces two important considerations into the analysis of tensile deformation: 1) the volume of the deforming region decreases from that of the entire gauge section to a smaller, generally unknown value in the vicinity of

Invited Paper 1O-109 received Mar. 31, 1982; revised manuscript received Apr. 14, 1982; accepted for publication Apr. 14, 1982; received by Managing Editor Apr. 26, 1982.

(c) 1982 Society of Photo-Optical Instrumentation Engineers. the neck; 2) the stress distribution across the minimum cross section changes from a uniform, uniaxial state of stress to a nonuniform, multiaxial state of stress. A correction for the cross section of the deforming region requires only an instantaneous measurement, but correction for triaxiality of the stress distribution introduced by the neck demands more careful analysis. Additional complications may arise if plastic anisotropy causes the specimen shape to deviate from its initial axisymmetry.

Two approaches have been used to correct stress-strain data for necking. Direct methods rely on elimination of the neck by machining or cold working specimens at various stages of the test after flow localization has occurred..$^{1-3}$ Indirect measurements utilize analytical expressions related to the shape of the specimen to correct the apparent stress for triaxiality. ${ }^{4-7}$ All indirect methods require simultaneous measurements of the dimensions of the minimum cross section normal to the loading axis and $\mathrm{R}$, the radius of curvature of the specimen profile measured at the minimum section. The most widely used method, suggested by Bridgman, ${ }^{6}$ states that for an axisymmetric specimen

$\sigma_{\mathrm{t}}=\sigma\{[1+(\mathrm{R} / 2 \mathrm{a})] \ln [1+(\mathrm{a} / 2 \mathrm{R})]\}^{-1}$,

where $\sigma_{t}$ is the corrected uniform true axial stress and $\sigma$ is the measured true axial stress on the minimum cross section, respectively; a represents the radius of the minimum cross-sectional dimension. An extension to special cases of nonaxisymmetry has been proposed by Eisenberg. ${ }^{7}$

Obtaining accurate experimental values of $R$ presents a difficult problem. Most techniques rely on incremental tests, between which measurements are made by optical ${ }^{8}$ or mechanical methods. ${ }^{2,3,6,9}$ Continuous measurements require calibration with an incremental technique to ensure accuracy. ${ }^{10}$ Finally, choice of an appropriate analytical correction requires detailed knowledge of the evolution of 


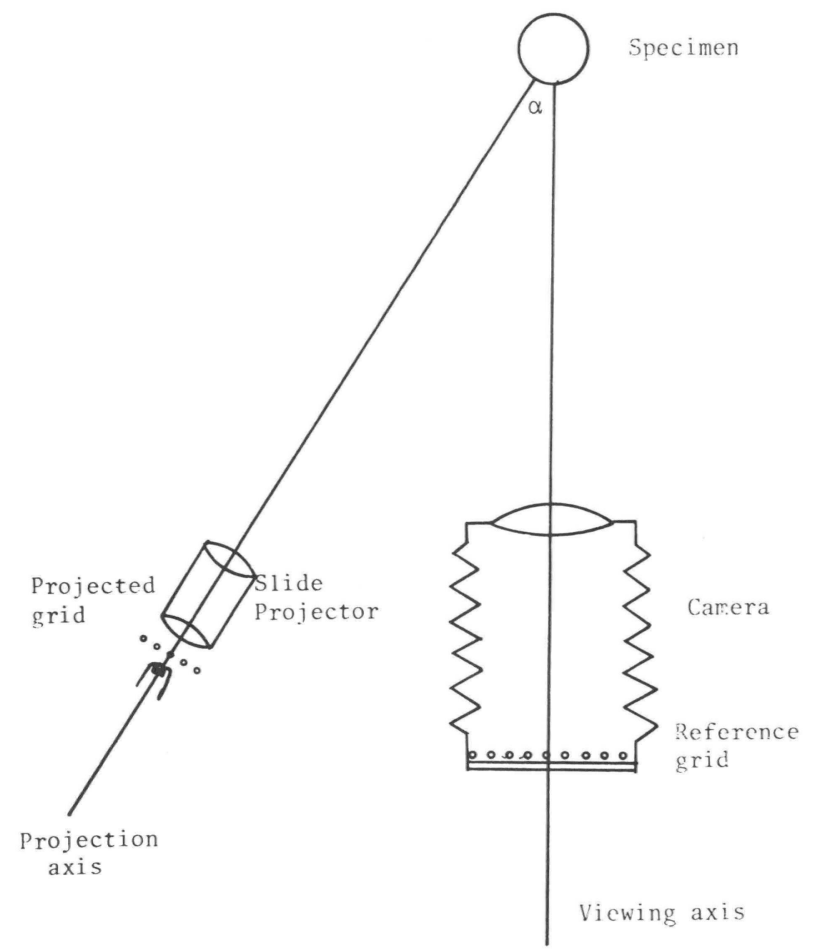

Fig. 1. Schematic diagram of the projection moire apparatus.

the specimen shape during the test.

The present work describes an application of the projection moire technique to determine $\mathrm{R}$ and to verify axial symmetry. This procedure offers a powerful method of obtaining measurements required for analytical corrections and for quantitative measurements of the specimen shape.

\section{PRINCIPLES OF MEASUREMENT}

\subsection{Projection moire method}

The projection moire method is a modification of the shadow moire method. Shadow moire requires the grating to be at least as large as the surface being studied, making it inconvenient for large structures. Projection moire overcomes this limitation by projecting an image of a grid on the surface being studied, using a slide projector. This method is, therefore, capable of handling both large and small structures.

The projection moire method discussed here is a single projector, single exposure method. A slide projector projects an image of a grid on the specimen surface. A camera then forms an image of the specimen on a second grid, the reference grid. Photographic film mounted against the reference grid is used to record the final image. Figure 1 shows the schematic drawing of the projection moire setup. Moire fringes are seen on the final image of the specimen, as shown in Fig. 2.

Projection moire has been extensively investigated by others. ${ }^{11-16}$ The approach to the derivations in this paper is substantially different from that in other analyses. However, the results'are consistant with previous investigations.

\subsection{Theory of the method}

Clave $^{17}$ showed that the moire fringes are the intersection lines between a set of surfaces given by an equation of the form*

$\mathrm{Ax}^{2}+\mathrm{By}^{2}+\mathrm{Cxy}+\mathrm{Dx}+\mathrm{Ey}+\mathrm{F}=0$

\footnotetext{
*Derivation of equations used in this section comprises Appendix A.
}
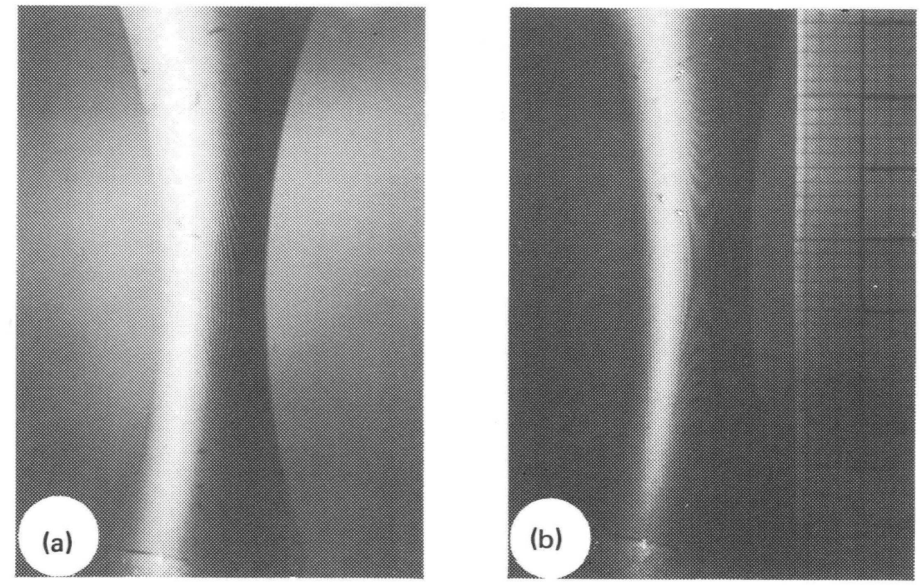

Fig. 2. Image of a specimen: a) without reference grid; b) with reference grid.

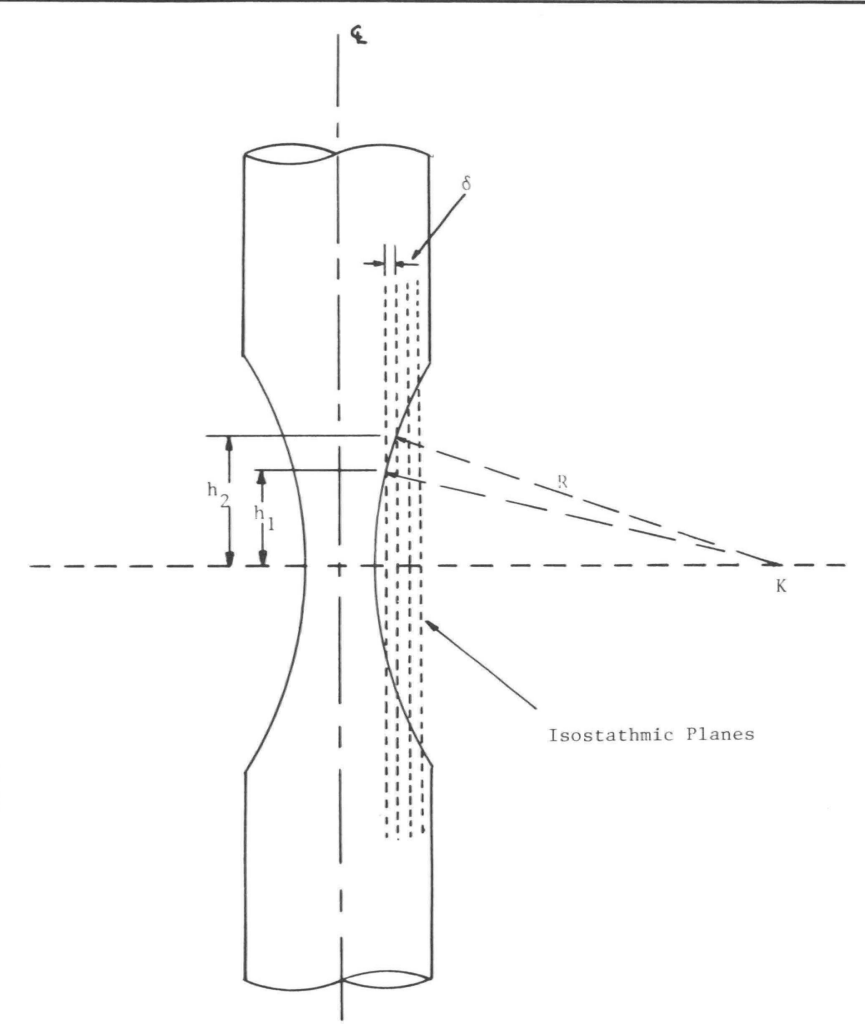

Fig. 3. Relation between neck profile radius $R$, spacing of isostathmic planes $\delta$ and the distances $h_{1}$ and $h_{2}$ of the first two moire fringes from the minimum cross section.

and the specimen surface.

If the pitches of the grids are small compared to the distances of the camera and projector from the specimen, these surfaces can be approximated as a set of equally spaced parallel planes, the spacing between which is given by

$$
\delta=\frac{\mathrm{p}_{1} \mathrm{p}_{2}}{\left(\mathrm{p}_{1}^{2}+\mathrm{p}_{2}^{2}-2 \mathrm{p}_{1} \mathrm{p}_{2} \cos \alpha\right)^{1 / 2}},
$$

where $\delta$ equals the spacing between planes, $\mathrm{p}_{1}$ and $\mathrm{p}_{2}$ represent pitches of the projected and reference gratings at the specimen surface, and $\alpha$ is the angle between projection and viewing axes. The effective pitches $p_{1}$ and $p_{2}$ depend on the pitches of the projected and 
reference grids, the focal lengths of projector and camera lenses, and the distances of the lenses from the specimen.

The above equations assume the grid lines to be parallel. Any rotation of one grid with respect to the other changes the value of $\delta$, the sensitivity of the instrument. The sensitivity of the measurements, therefore, depends on the actual physical dimensions of the optical setup, specifically the pitches of the grids, the angle between them, and the angle between the projection and viewing axes.

\subsection{Measurement of profile radius}

To measure the profile radius of curvature, the specimen forms the target of the projection moire apparatus. The curved surface of the specimen intersects several of the parallel planes resulting in moire fringes as shown in Fig. 2(b). Approximating the profile of the specimen at the minimum cross section by an arc of a circle, the geometry illustrated in Fig. 3 gives

$\mathrm{R} \simeq \frac{\mathrm{h}_{2}^{2}-\mathrm{h}_{1}^{2}}{2 \delta}$,

where $h_{1}$ and $h_{2}$ are the distances of the first two moire fringes from the minimum cross section.

\section{EXPERIMENTAL PROCEDURE}

\subsection{Apparatus}

The moire optical apparatus consisted of two Ronchi rulings, a Beseler Slide King $31 / 4$ in. $\times 4$ in. lantern slide projector, and a bellows type Arca Swiss camera mounted on a rack and pinion so both lens and ground glass screen could be moved independently. Pictures were taken on Polaroid PN 55 film using a Polaroid 545 Land film holder mounted between the ground glass screen of the camera and the reference grid. The projected grid had 200 lines per inch. The reference grid could be changed depending on the sensitivity required.

\subsection{Calibration of the instrument}

The sensitivity of the instrument can be determined using Eq. (3) if $\mathrm{p}_{1}$, $\mathrm{p}_{2}$, and $\alpha$ are known. An experimental calibration is also possible by observing the moire fringe pattern on specimens of known shape. The latter procedure was adopted.

The moire fringe pattern on a specimen shaped as shown in Fig. 4 was used to calibrate the instrument. If the diameters $a$ and $b$ of the specimen at the two ends of the tapered zone are known and the number of fringes $\mathrm{N}$ in this region are counted, the sensitivity is simply

$\delta=\frac{\mathrm{b}-\mathrm{a}}{2 \mathrm{~N}}$.

For the example illustrated in Fig. 4, the diameters a and b were 0.599 and $1.191 \mathrm{~cm}$ respectively, and 17 fringes were counted on the specimen. This gave an experimental value of $\delta=0.01741 \mathrm{~cm}$, which was about $10 \%$ higher than the sensitivity calculated from Eq. (3). the reasons for this are discussed in Sec. 5.1.

\subsection{Procedure}

Incremental tension tests were performed on two materials, commercially pure copper and mild steel $(0.05 \% \mathrm{C})$ on a $10,000 \mathrm{lb}$ Instron testing machine. Figure 5 shows the two types of specimens used: straight specimens with a uniform initial cross section and specimens with an initial curved profile machined in them. Table I lists the specimens tested.

The specimens were pulled at a constant crosshead speed of 0.05 in./ min. Load was recorded on a strip chart recorder. Tests were interrupted at different stages to measure the diameter at the minimum cross section using vernier calipers. In the case of necked specimens, i.e., specimens in which the cross section was not uniform, they were removed from the testing machine and mounted on

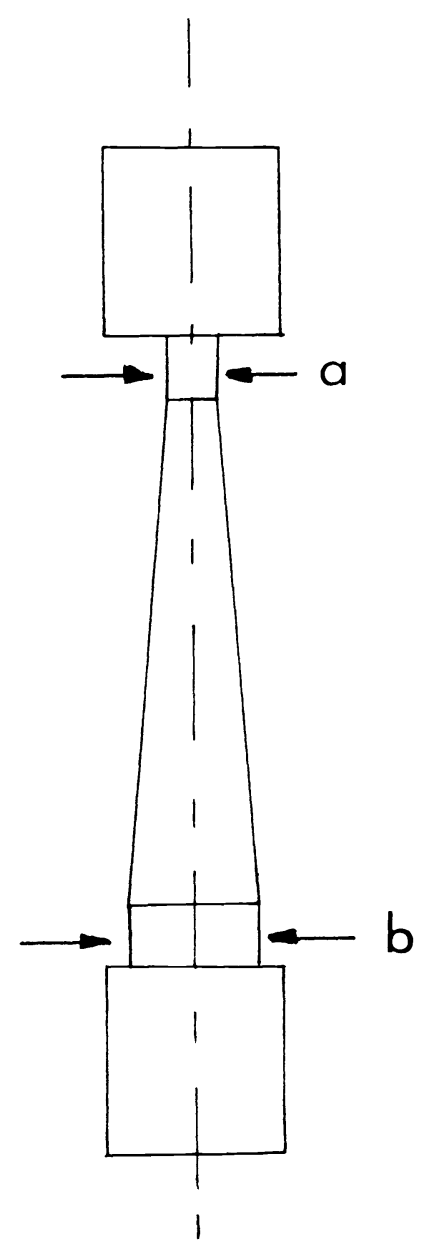

Fig. 4. Calibration specimen.

TABLE I. Specimens Tested

\begin{tabular}{lccc}
\hline Material & Specimen no. & $\begin{array}{c}\text { Initial cross-section } \\
\text { diameter }(\mathrm{cm})\end{array}$ & $\begin{array}{c}\text { Initial profile } \\
\text { radius }(\mathrm{cm})\end{array}$ \\
\hline Copper & $\mathrm{A}$ & 1.27 & $\infty$ \\
& $\mathrm{B}$ & 1.27 & 11.15 \\
Mild steel & $\mathrm{C}$ & 1.25 & 5.84 \\
& 1 & 0.980 & $\infty$ \\
& 2 & 0.925 & 7.14 \\
& 3 & 0.932 & 5.99 \\
\hline
\end{tabular}

the projection moire apparatus to measure the file radius. Figures 6 and 7 show the growth of the neck in the two types of specimens that were tested.

Continuous tests were also conducted on samples of the two materials for comparison with the interrupted tests. Specimens were tested at a constant true plastic strain rate of $0.05 / \mathrm{sec}$ on the system described by Hartley and Jenkins. ${ }^{10}$

\section{RESULTS}

Figure 8 shows the uncorrected flow curves of two copper specimens, A and B. Specimen B, which had an initial profile radius of $11.15 \mathrm{~cm}$, supported a larger stress than specimen $A$, at all strains. Figure 9 shows the corrected flow curves of the three copper specimens, and Fig. 10 shows the corresponding curves for the mild steel specimens. In each case the corrected flow curves coincide.

Figures 11 and 12 show the results of the continuous tests. A few points from the interrupted tests have been marked for comparison. 


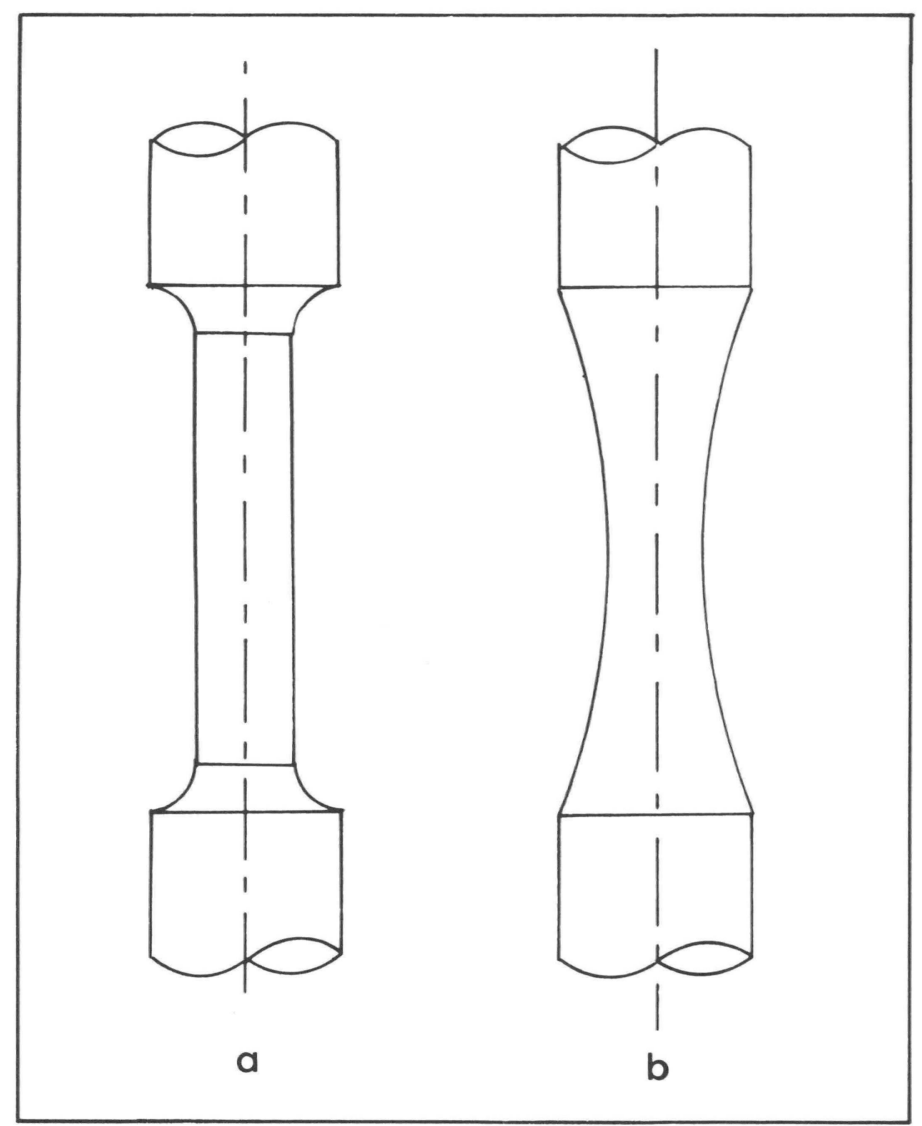

Fig. 5. Shapes of the two types of specimens tested: a) Straight-sided (uniform cross section) specimen; b) Profiled (nonuniform cross section) specimen.
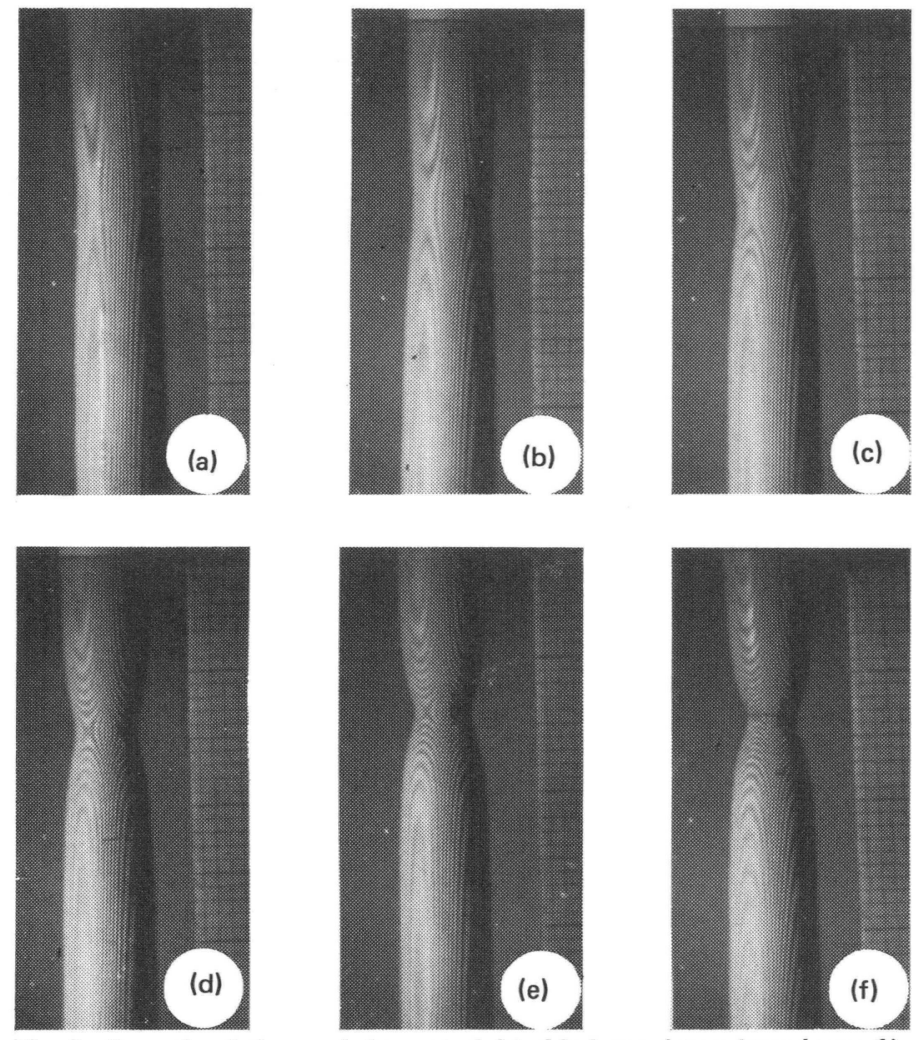

Fig. 6. Growth of the neck in a straight-sided specimen (specimen 1). Pictures were taken at strains of a) 0.45 ; b) 0.57 ; c) 0.71 ; d) 1.00 ; e) 1.23; f) 1.46 (at fracture).
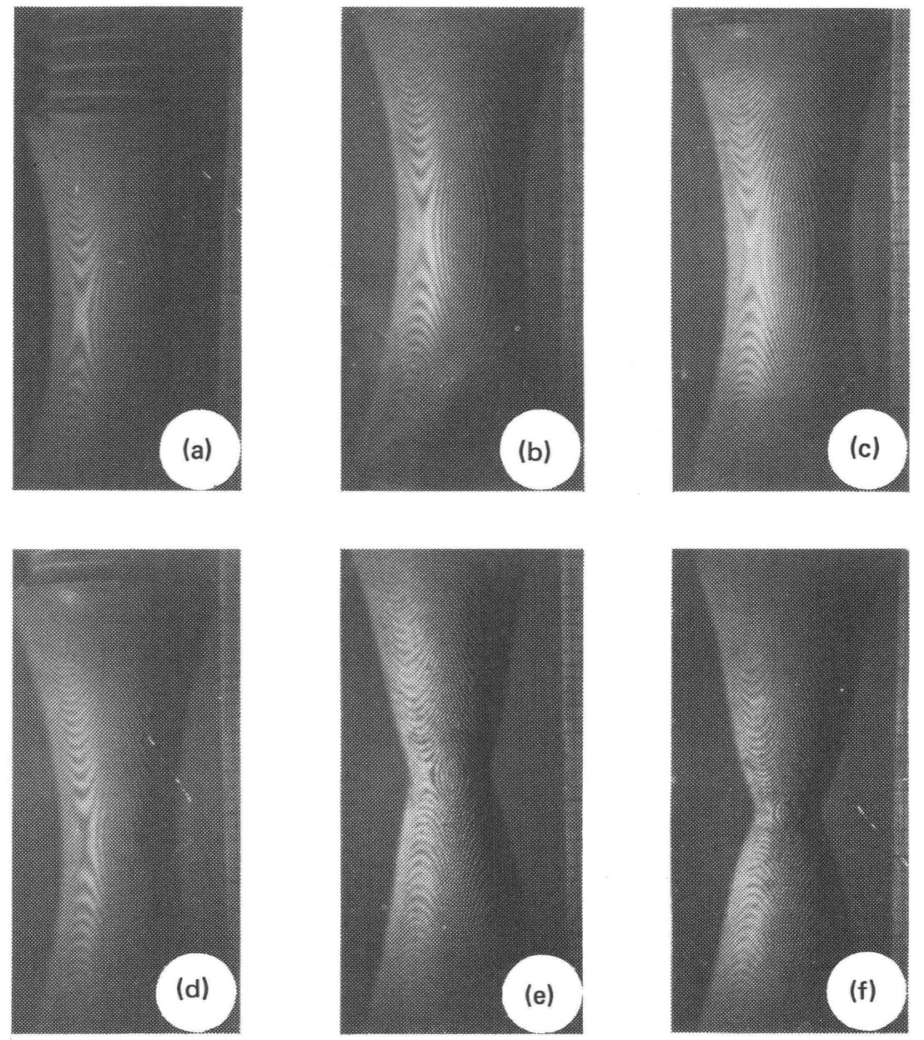

Fig. 7. Growth of the neck in a profiled specimen (specimen C). Pictures were taken at strains of a) 0.00 ; b) 0.12 ; c) 0.16 ; d) 0.32 ; e) $0.98 ;$ f) 1.47 .

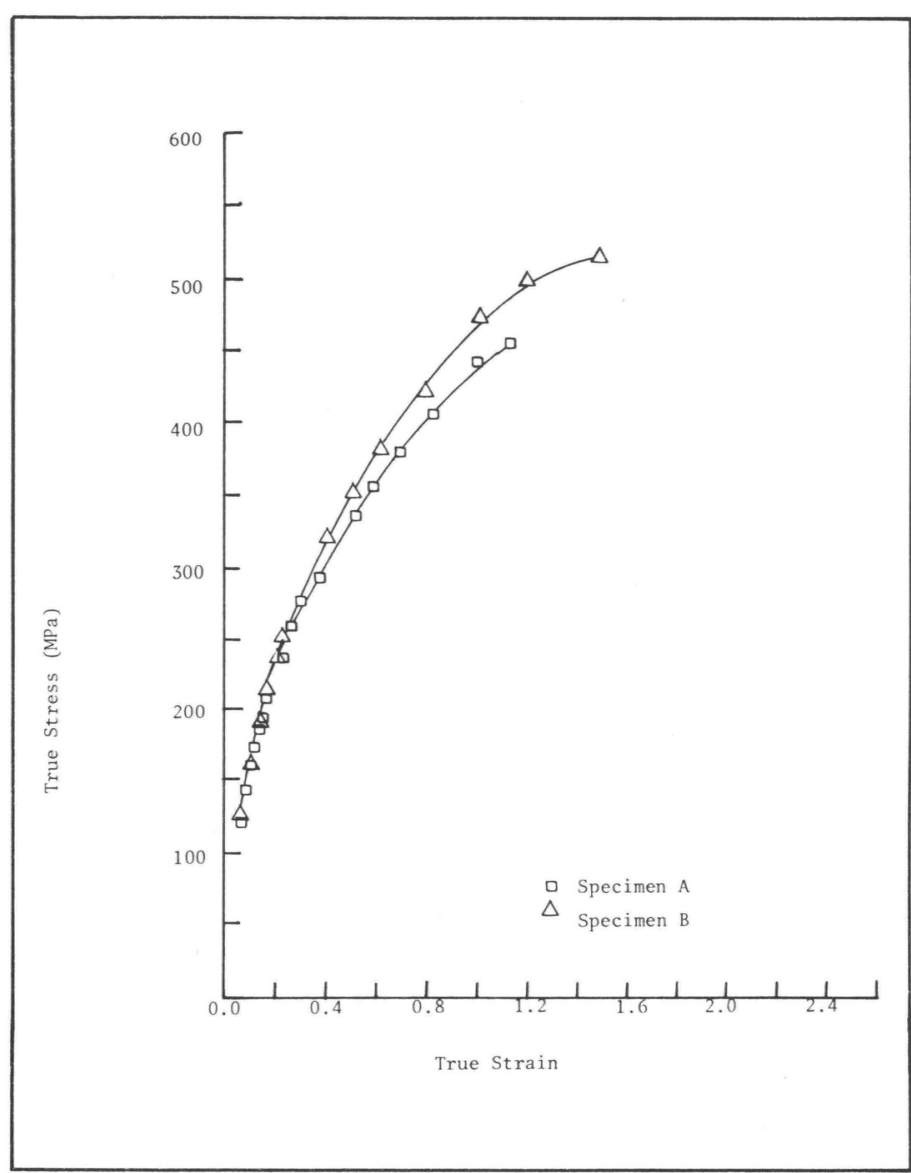

Fig. 8. Comparison of the uncorrected flow curves of a straight-sided specimen A and a profiled specimen B. Flow curve of B is higher.

\section{8 / OPTICAL ENGINEERING / July/August 1982 / Vol. 21 No. 4}

Downloaded From: http://opticalengineering.spiedigitallibrary.org/ on 06/25/2013 Terms of Use: http://spiedl.org/terms 


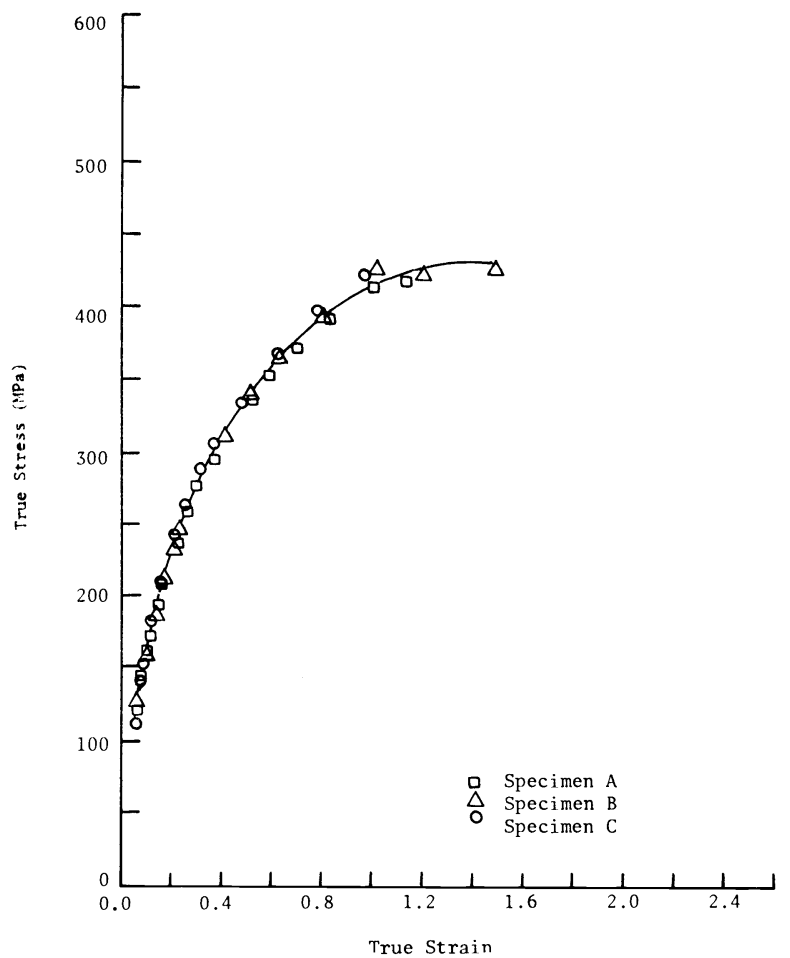

Fig. 9. Corrected flow curves for copper specimens A, B, and C.

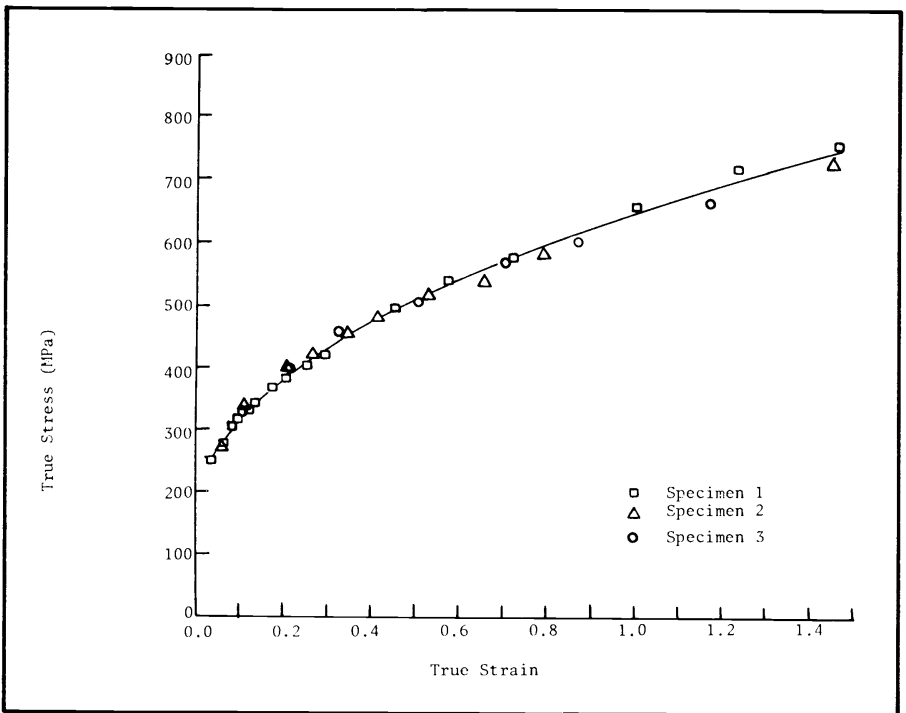

Fig. 10. Corrected flow curves for mild steel specimens 1,2 , and 3.

The results of the two tests coincide for copper, while for mild steel the flow curve of the continuous test lies below the curve for the interrupted tests.

Figure 13 shows the variation of the neck profile radius with strain for specimen B, a behavior typical of all specimens with an initial nonuniform cross section. The profile radius increased and decreased a few times in the initial stages of the test. Later, when flow became localized, the radius decreased continuously.

All copper specimens failed at an apparent strain $\epsilon=2 \ln \left(a_{0} / a_{f}\right)$ $=2.4$, with $\mathrm{a}_{\mathrm{o}}$ and $\mathrm{a}_{\mathrm{f}}$ representing the diameters of the minimum cross section initially (o) and at fracture (f), respectively. They exhibited a deep double-cup fracture. The steel specimens failed with a cup and cone fracture at a strain of about 1.45 .

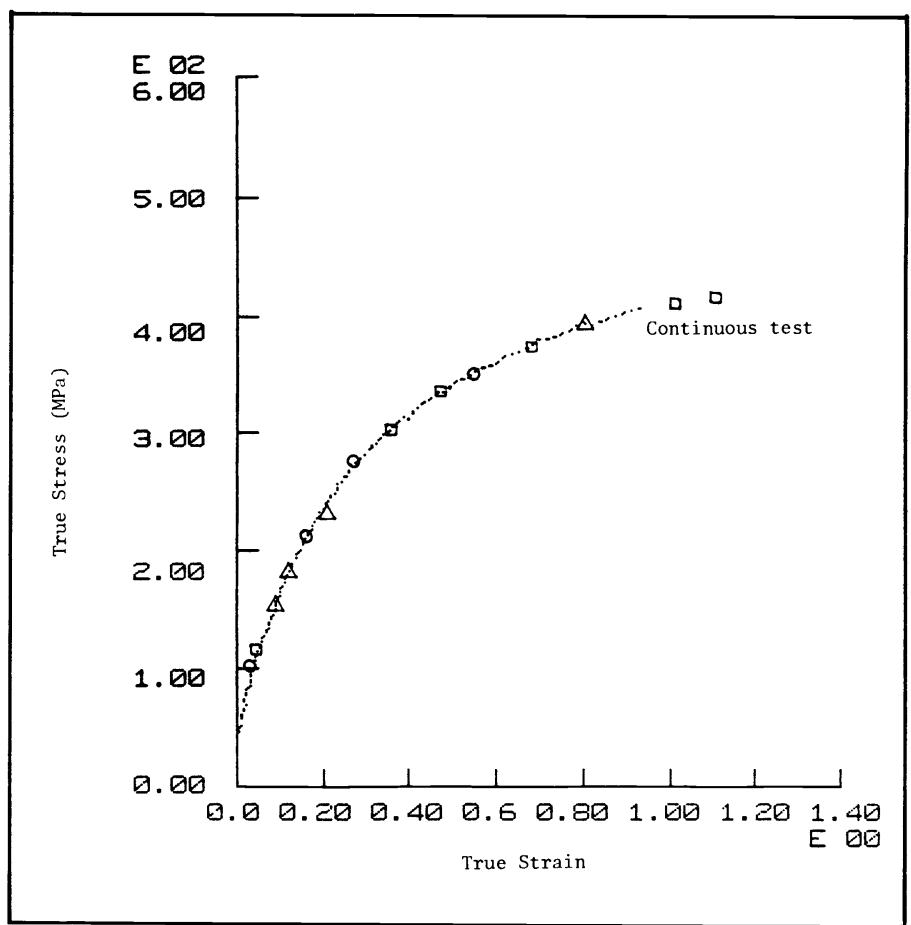

Fig. 11. Comparison between the flow curves obtained by a continuous test and interrupted tests for copper.

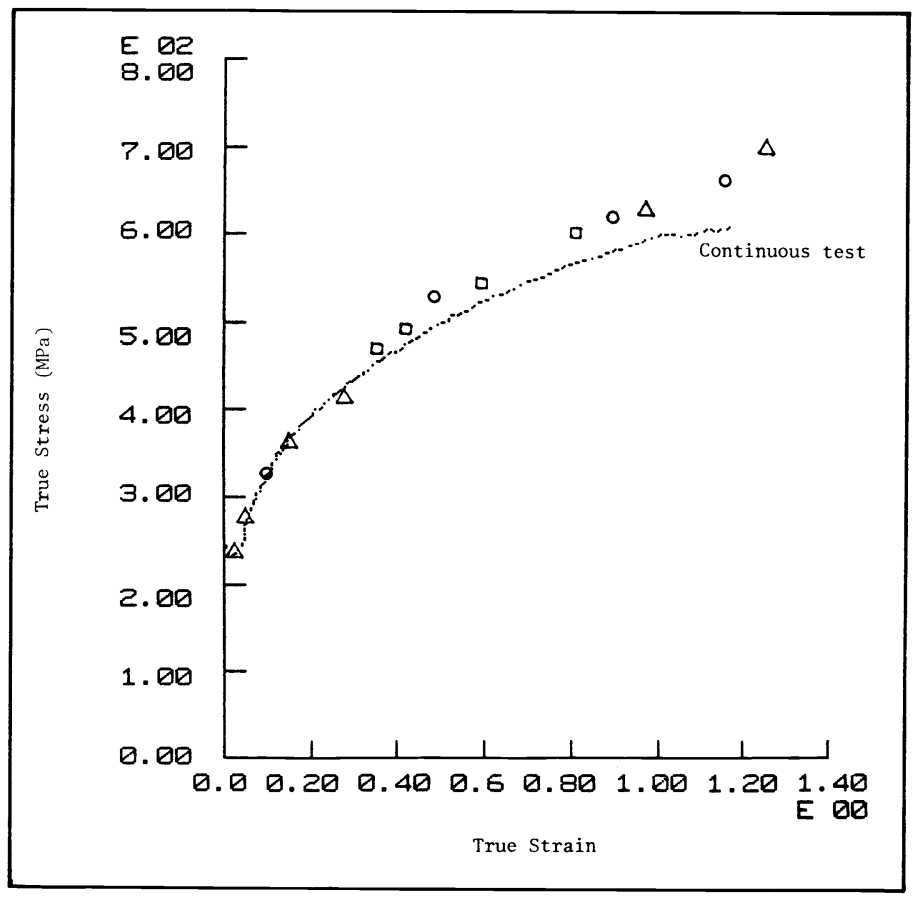

Fig. 12. Comparison between the flow curves obtained by a continuous test and interrupted tests for mild steel.

\section{DISCUSSION}

\subsection{Calibration}

The experimental value of the sensitivity $\delta$ was found to be higher than the value calculated using Eq. (3). One of the reasons for this is the approximations used to simplify the analysis. The more general equation (Eq. (2) and Eq. (A.6)) would yield better values of $\delta$.

\subsection{Measurements on specimens}

Application of the Bridgman correction to the measured stressstrain curves of incrementally tested copper and steel resulted in 


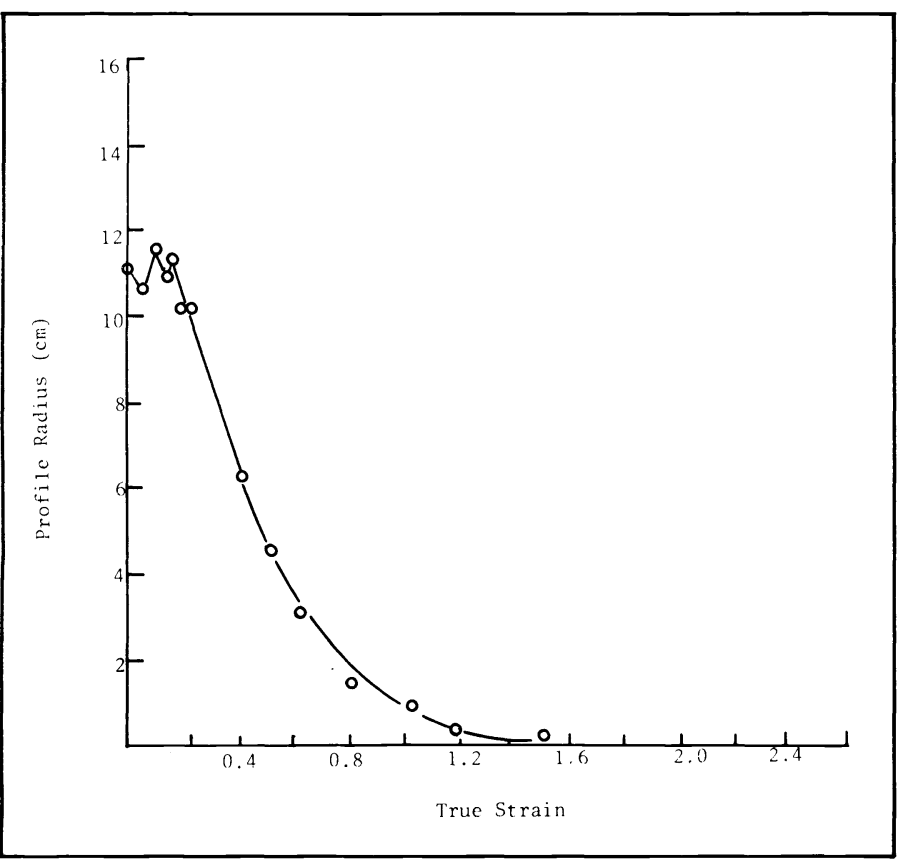

Fig. 13. Variation of the neck profile radius with strain for specimen $B$.

consistent results for each material regardless of the original specimen profile. This result does not support the assumption underlying the correction but merely indicates that it yields self-consistent results. Initial yielding in specimens having curved profiles led to a period of uniform deformation in which the effective value of $R$ increased above that machined into the original specimen. When flow localization began, the value of $R$ decreased with strain in approximately the same manner as for initially straight specimens.

Comparison of incremental tests with continuous tests revealed that the variation of $\mathrm{R}$ with strain apparently depends on the strain rate. The more rate-sensitive steel specimens did not exhibit the same correction for incrementally loaded and continuously tested material, while the less rate-sensitive material, copper, showed substantially the same results for both types of tests. This suggests that the correction term must be modified to account for strain-rate sensitivity of the material.

Analysis of the fringe pattern provides a simpler determination of $\mathrm{R}$ than measurements made directly on a silhouette of the specimen profile. This condition arises because of the difficulty in illuminating the specimen uniformly over the region of interest to provide sharp edges of the silhouette image. In addition, the fringe patterns provide a more vivid display of the symmetry of the specimen shape.

\section{CONCLUSIONS}

An accurate method for the determination of profile radii of curvature of necked tensile specimens has been described. The projection moire method is a powerful technique for studying the geometry of the neck. The method would be very useful to study anisotropic materials, like Zircaloy, which neck nonsymmetrically.

It should be noted that the analysis of projection moire as presented in this paper can only be applied to the determination of necking radii of tensile test specimens. It cannot be directly applied to the determination of general surface topography, for which other analyses ${ }^{11-16}$ are more appropriate.

\section{ACKNOWLEDGMENTS}

The work presented in this paper is from the theses submitted by Jérôme Clave ${ }^{17}$ and Raghavan Srinivasan ${ }^{18}$ in partial fulfillment of the requirements for the degree of Master of Engineering in Materials Science and Engineering, University of Florida. Support for the work by the U. S. Nuclear Regulatory Commission, Contract No. NRC-04-77-039, is gratefully acknowledged.

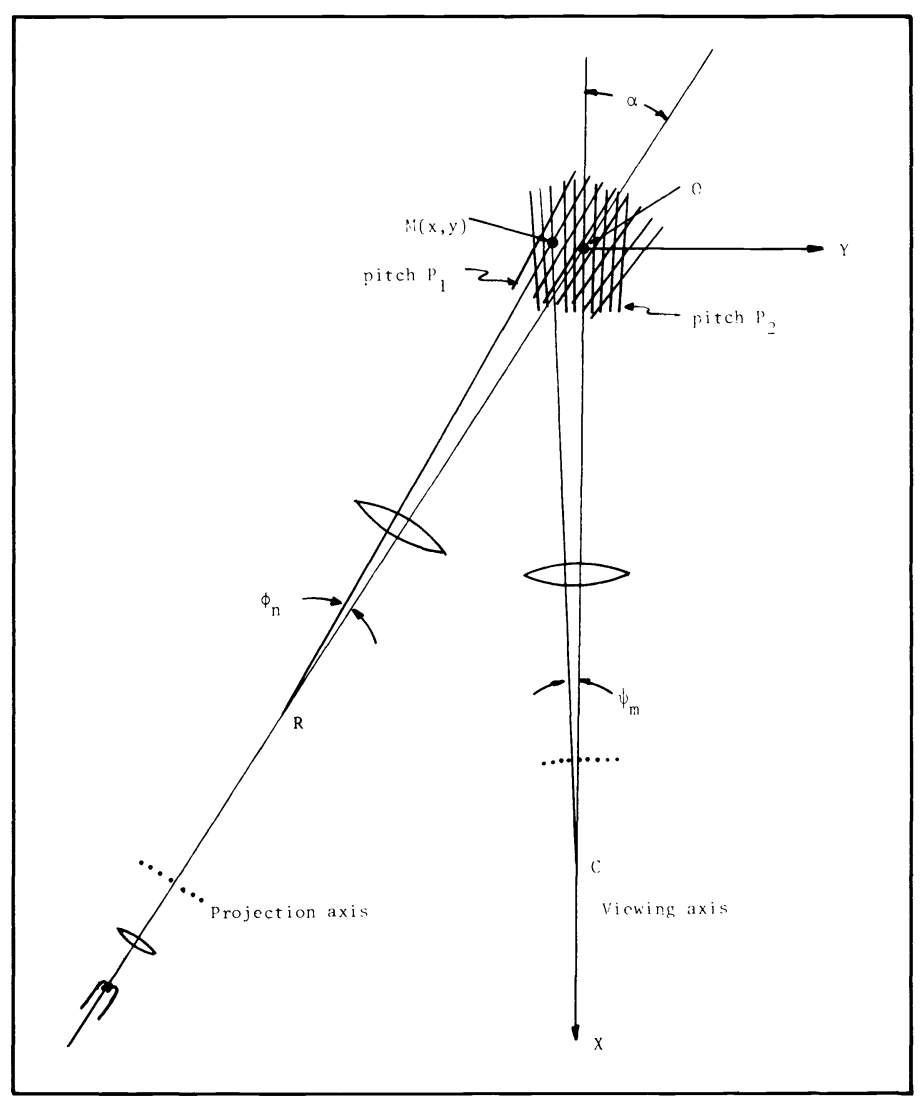

Fig. A.1. Optical model to the projection moire method.

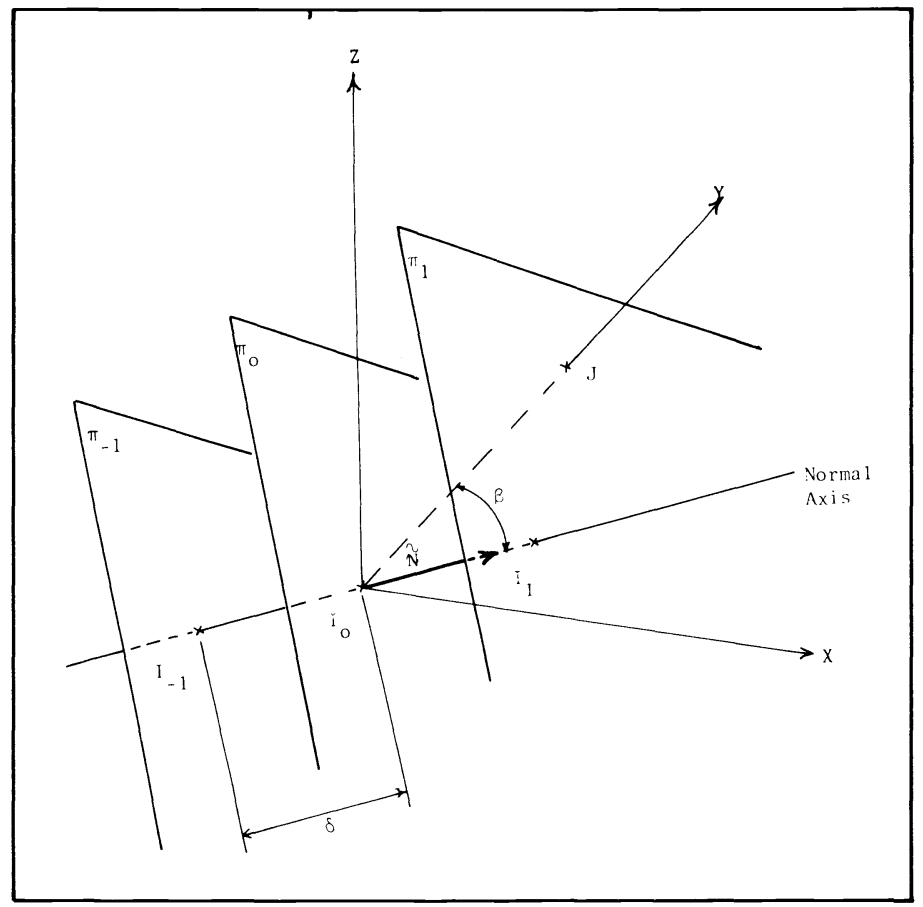

Fig. A.2. Isostathmic planes.

\section{APPENDIX A: GENERAL EQUATIONS OF THE MOIRE FRINGES}

Figure A.l shows a schematic drawing of the projection moire apparatus. $\mathrm{O}$ is the origin of a Cartesian coordinate frame XOY. Light and dark rays which make up the images of the reference and projected grids radiate from points $C$ and $R$, respectively, and inter- 
sect in a region around the origin $O$.

$M(x, y)$, a point on the surface being studied, is the intersection of the $n$-th line of the projected grid image with the m-th line of the reference grid image. The point $\mathrm{M}(\mathrm{x}, \mathrm{y})$ subtends angles $\phi_{\mathrm{n}}$ and $\psi_{\mathrm{m}}$ at the optical nodal points $\mathrm{R}$ and $\mathrm{C}$ :

$\tan \phi_{\mathrm{n}}=\frac{\mathrm{np}_{1}}{\mathrm{OR}}$

and

$\tan \psi_{\mathrm{m}}=\frac{\mathrm{mp}_{2}}{\mathrm{OC}}$

where $p_{1}$ and $p_{2}$ are the pitches of the images of the projected and reference grids in the vicinity of the origin $\mathrm{O}$.

Also,

$\tan \phi_{\mathrm{n}}=\frac{-\mathrm{x} \sin \alpha+\mathrm{y} \cos \alpha}{\mathrm{OR}-\mathrm{x} \cos \alpha+\mathrm{y} \sin \alpha}$,

and

$\tan \psi_{\mathrm{m}}=\frac{\mathrm{y}}{\mathrm{OC}-\mathrm{x}}$

By the equation for moire fringes, point $M$ would lie on the k-th fringe of a subtraction moire fringe pattern, where

$\mathrm{k}=\mathrm{m}-\mathrm{n}, \quad \mathrm{k}, \mathrm{m}, \mathrm{n},=0, \pm 1, \pm 2, \ldots$

Substituting the values of $m$ and $n$ from Eqs. (A.1) to (A.4) in Eq. (A.5), we get

$\mathrm{Ax}^{2}+\mathrm{By}^{2}+\mathrm{Cxy}+\mathrm{Dx}+\mathrm{Ey}+\mathrm{F}=0$,

where

$\mathrm{A}=\mathrm{p}_{2}\left(\mathrm{OR} \sin \alpha-\mathrm{kp}_{1} \cos \alpha\right)$,

$\mathrm{B}=\mathrm{OCp}_{1} \sin \alpha$,

$\mathrm{C}=\left(\mathrm{ORp}_{2}-\mathrm{OCp_{1 }}\right) \cos \alpha+\mathrm{kp}_{1} \mathrm{p}_{2} \sin \alpha$,

$\mathrm{D}=\mathrm{p}_{2}\left[\mathrm{kp}_{1}(\mathrm{OR}+\mathrm{OC} \cos \alpha)-\mathrm{OR} \cdot \mathrm{OC} \sin \alpha\right]$,

$\mathrm{E}=\mathrm{OC}\left[\mathrm{OR}\left(\mathrm{p}_{1}-\mathrm{p}_{2} \cos \alpha\right)-\mathrm{kp}_{1} \mathrm{p}_{2} \sin \alpha\right], \quad$ and

$\mathrm{F}=-\mathrm{kp}_{1} \mathrm{p}_{2} \mathrm{OC} \times \mathrm{OR}$.

Each moire fringe is the intersection line between the surface being studied and a cylindrical surface, the axis of which is parallel to the two vertical gratings. Certain approximations can be made that make Eq. (A.6) easier to analyze. Since OR and OC $(\sim 10 \mathrm{~cm})$ are much larger than $p_{1}$ and $p_{2}\left(\sim 10^{-2} \mathrm{~cm}\right)$, higher order terms drop out of Eq. (A.6), which can then be rewritten as

$$
\begin{gathered}
\mathrm{y}=\frac{\mathrm{p}_{2} \sin \alpha}{\mathrm{p}_{1}-\mathrm{p}_{2} \cos \alpha} \mathrm{x}-\frac{\mathrm{kp}_{1} \mathrm{p}_{2}}{\mathrm{p}_{1}-\mathrm{p}_{2} \cos \alpha}, \\
\mathrm{k}=0, \pm 1, \pm 2, \ldots
\end{gathered}
$$

This is equivalent to assuming that the two beams that intersect at $O$ are made up of parallel rays. The moire fringes can now be considered as the intersection lines between a set of parallel equally spaced planes, the isostathmic planes, and the surface being studied. The spacing $\delta$ between the planes is the sensitivity of the projection moire method.

In Fig. A.2, the normal vector to the isostathmic planes is

$\widetilde{N}=\frac{p_{2} \sin \alpha}{p_{1}-p_{2} \cos \alpha} \vec{i}-\vec{j}$.
Planes $\pi_{-1}, \pi_{0}$, and $\pi_{1}$ are planes corresponding to $\mathrm{k}=-1,0$, and 1 , respectively. $\mathrm{I}_{0}(0,0,0)$ and

$\mathrm{J}_{1}\left(0, \frac{-\mathrm{p}_{1} \mathrm{p}_{2}}{\mathrm{p}_{1}-\mathrm{p}_{2} \cos \alpha}, 0\right)$

are points on $\pi_{0}$ and $\pi_{1} . \widetilde{N}$ intersects $\pi_{0}$ and $\pi_{1}$ at $\mathrm{I}_{0}$ and $\mathrm{I}_{1}$, respectively.

We have

$\mathrm{I}_{0} \mathrm{I}_{1}=\delta=\mathrm{I}_{0} \mathrm{~J}_{1} \cos \beta$,

where

$\cos \beta=\frac{\widetilde{N} \cdot \vec{j}}{|\widetilde{N}|}$,

$\mathrm{I}_{0} \mathrm{~J}_{1}=\frac{\mathrm{p}_{1} \mathrm{p}_{2}}{\mathrm{p}_{1}-\mathrm{p}_{2} \cos \alpha}$,

$|\widetilde{N}|=\frac{\left.p_{1}^{2}+p_{2}^{2}-2 p_{1} p_{2} \cos \alpha\right)^{1 / 2}}{p_{1}-p_{2} \cos \alpha} ;$

$\therefore \quad \delta=\frac{\mathrm{p}_{1} \mathrm{p}_{2}}{\left(\mathrm{p}_{1}^{2}+\mathrm{p}_{2}^{2}-2 \mathrm{p}_{1} \mathrm{p}_{2} \cos \alpha\right)^{1 / 2}}$,

where $\delta$ is the spacing between the planes.

If the grid lines are not parallel, the equations are to be modified. If the reference grid is rotated by an angle $\gamma$ with respect to the projected grid about the $\mathrm{x}$ axis, then the equations describing the intersecting rays change from

$y=-x \tan \alpha+\frac{m p_{1}}{\cos \alpha}$,

and

$\mathrm{y}=\mathrm{np}_{2}$

to

$y=-x \tan \alpha+\frac{m p_{1}}{\cos \alpha}$,

and

$\mathrm{y}=\mathrm{z} \tan \gamma+\frac{\mathrm{np}_{2}}{\cos \gamma}$.

The resulting isostathmic planes are defined by

$$
\begin{aligned}
\mathrm{y} & =\frac{\mathrm{p}_{2} \sin \alpha}{\mathrm{p}_{1} \cos \gamma-\mathrm{p}_{2} \cos \alpha} \mathrm{x}+\frac{\mathrm{p}_{1} \sin \gamma}{\mathrm{p}_{1} \cos \gamma-\mathrm{p}_{2} \cos \alpha} \mathrm{z} \\
& +\frac{\mathrm{kp}_{1} \mathrm{p}_{2}}{\mathrm{p}_{1} \cos \alpha-\mathrm{p}_{2} \cos \alpha} .
\end{aligned}
$$

The spacing between these planes can be shown to be

$$
\delta=\frac{\mathrm{p}_{1} \mathrm{p}_{2}}{\left(\mathrm{p}_{1}^{2}+\mathrm{p}_{2}^{2}-2 \mathrm{p}_{1} \mathrm{p}_{2} \cos \alpha \cos \gamma\right)^{1 / 2}}
$$


The sensitivity of the system, therefore, is a function of the projected viewing grid pitches, the angle $\gamma$ between the grid lines, and the angle $\alpha$ between the projection and viewing axes. The sensitivity increases ( $\delta$ decreases) with increasing $\alpha$ and $\gamma$.

\section{REFERENCES}

1. Kuntze, W., Mitteilung aus dem Materialprüfungsamt und dem KaiserWilhelm Institut für Metallforshung, 42, 31(1924).

2. Thomsen, E. G., Shabaik, A. H., and Sohrabpour, S., Trans. ASME, J. Engineering Materials and Technology, 252 (July 1977).

3. Thomsen, E. G., Shabaik, A. H., and Sohrabpour, S., Fifth North American Metalworking Research Conf. Proc., 139 (May 1977).

4. Siebel, E., Verein deutcher Eisenhüttenleute, Berlin 75, (1925).

5. Davidenkov, N. N. and Spiridonova, N. I., Proc. ASTM 32, 553(1944).

6. Bridgman, P. W., Rev. Mod. Phys. 17, 3(1945).

7. Eisenberg, M. A., "Stress Distributions in the Necks of Tension Specimens of Anisotropic and Isotropic Materials," Properties of Reactor Materials at Constant True Strain Rates, Final Report July 1978-June 1980,
NUREG/CR-0235, U.S. Nuclear Regulatory Commission.

8. Trozera, T. A., Trans. ASM 56, 780(1963).

9. Marshall, E. R. and Shaw, M. C., Trans. ASM 44, 705(1952).

10. Hartley, C. S. and Jenkins, D. A., J. Metals 32(7), 23(1980).

11. Khetan, R. P., "Theory and Applications of Projection Moire Methods," Ph.D. Thesis, Dept. of Mechanics, State University of New York at Stony Brook (May 1975).

12. Wasowski, J., Opt. Commun. 2(7), 3213(1970).

13. Hovanesian, J. Der, and Hung, Y. Y., Appl. Opt. 10(12), 273(1971).

14. Hovanesian, J. Der, Haskell, R. E., and Powell, R. L., Proc. Eng. Applications of Holography, Los Angeles 377(Feb. 1972).

15. Khetan, R. P. and Chiang, F. P., Developments in Mechanics, Vol. 8 , Proc. 15th Midwestern Mechanics Conf. University of Illinois, Chicago Circle, 16 (March 1977).

16. Idesawa, M., Yatagai, T., and Soma, T., Appl. Opt. 16(8), 2152(1977)

17. Clave, J. "Fullfield Out-of-Plane Displacement Measurement by a Moire Method," M.S. Thesis, Dept. of Materials Science and Engineering, University of Florida (Dec. 1978).

18. Srinivasan, R. "Correction of the Tensile Flow Curve for Triaxial Stresses at the Neck by the Projection Moire Method," M. E. Thesis, Dept. of Materials Science and Engineering, University of Florida (June 1980). ङ 